\title{
PREVALENCE AND DETERMINANTS OF ECHOCARDIOGRAPHIC LEFT VENTRICULAR HYPERTROPHY AMONG HYPERTENSIVE PATIENTS IN A TERTIARY CARE HOSPITAL
}

\author{
ANUGYA APARAJITA BEHERA ${ }^{1}$, PRIYAMBADA PANDA ${ }^{1}$, DIPTI MOHAPATRA ${ }^{1}$, SURESH KUMAR BEHERA ${ }^{2}$, ARATI \\ MOHANTY ${ }^{1}$
}

${ }^{1}$ Department of Physiology, Institute of Medical Sciences and Sum Hospital, Bhubaneswar, Odisha, India. ${ }^{2}$ Department of Cardiology, Institute of Medical Sciences and Sum Hospital, Bhubaneswar, Odisha, India. Email: drdiptimohapatra@gmail.com

Received: 05 October 2017, Revised and Accepted: 15 December 2017

ABSTRACT

Objectives: This cross-sectional study was conducted during the year 2014-15 to determine the prevalence, pattern, and factors associated with left ventricular hypertrophy $(\mathrm{LVH})$ among hypertensive patients attending a tertiary care hospital.

Methods: A total of 400 eligible adult patients having essential hypertension were included in this study. After obtaining informed consent, all participants were examined with echocardiography and relevant information was collected using a well-structured questionnaire.

Results: The mean age of study population was $52.3 \pm 12.8$ in years. Mean systolic (SBP) and diastolic blood pressure (DBP) was $149.8 \pm 11.2$ and $94.7 \pm 4.9 \mathrm{mmHg}$, respectively. Among the study participants, 266 (66.5\%) had LVH and concentric hypertrophy was the predominant (64.3\%) LV geometric pattern. Multivariate logistic regression revealed that obesity, SBP, and DBP had significant positive association with LVH (p<0.05).

Conclusion: Liberal use of echocardiography in hypertensive patients could be useful in early diagnosis of LVH and guiding treatment decision. There should be emphasis on controlling SBP, DBP, and body mass index of hypertensive patients so that further cardiovascular complications can be prevented.

Key words: Left ventricular hypertrophy, Hypertension, Echocardiography, Geometric pattern.

(C) 2018 The Authors. Published by Innovare Academic Sciences Pvt Ltd. This is an open access article under the CC BY license (http://creativecommons. org/licenses/by/4. 0/) DOI: http://dx.doi.org/10.22159/ajpcr.2018.v11i4.22932

\section{INTRODUCTION}

Cardiovascular diseases (CVDs) constitute one of the major causes of death and disabilities in the world. An estimated 17.7 million people died from CVD in 2015, representing 31\% of all global deaths. Of the 17 million premature deaths (under the age of 70 ) due to noncommunicable diseases in 2015, $82 \%$ are in low- and middle-income countries, and $37 \%$ are caused by CVD [1]. It is predicted that there will be a $60 \%$ rise in hypertensive adult patients from 972 million in 2000 to 1.56 billion in 2025 worldwide [2]. Hypertension is a powerful predictor of cardiovascular morbidity and mortality with significant disability [3-5] and directly responsible for 57\% of all stroke deaths; $24 \%$ of all coronary heart disease deaths in India [6]. Blood pressure reduction is highly efficacious in protecting patients against stroke and stroke recurrence, especially on long-term basis [7].

Left ventricular hypertrophy (LVH) is one of the earliest manifestations of organ damage among hypertensive patients and is a strong independent predictor of cardiovascular mortality and morbidity [8-11]. It has been shown in various studies that the incidence of LVH increases with age, obesity, gender, and blood pressure [12-16]. The relationship between LV mass and the degree of obesity has also been demonstrated by the Framingham study. Early diagnosis of $\mathrm{LVH}$, risk stratification, and aggressive treatment is essential to prevent cardiovascular morbidity and mortality [17]. It has been reported that assessment of cardiovascular risks among hypertensive patients are inadequate [18] and information regarding LVH in hypertensive patients is scarce, especially in this region. In this context, the present study was conducted with the aim to assess the prevalence and pattern of $\mathrm{LVH}$ and determine its associated factors among hypertensive patients.

\section{METHODS}

This is a cross-sectional descriptive study conducted at IMS and SUM Hospital, Bhubaneswar, in the Department of Cardiology/Physiology including 400 hypertensive patients who attended cardiology OPD from May 2014 to April 2015. All the study participants were explained about the nature and purpose of the study; informed consent was obtained before their participation in the study. All eligible study individuals were examined with echocardiography and relevant information was obtained using a well-structured questionnaire. Assuming the prevalence of echocardiographic LVH as 45\% [19] with absolute precision $5 \%$ and $95 \%$ confidence interval, the sample size was calculated as 380 . However, we included 400 patients in our study. The study was approved by the Institutional Ethics Committee of the authors' institution and all procedures followed were in accordance with appropriate ethical guidelines.

\section{Inclusion criteria}

Adults' $\geq 18$ years of age diagnosed to have essential hypertension with or without medication and willing to participate in the study.

\section{Exclusion criteria}

The presence of known cardiac diseases including valvular heart disease, coronary artery disease, conduction abnormalities; systemic diseases such as diabetes mellitus, chronic kidney disease, chronic obstructive pulmonary disease, tuberculosis, hepatic disease, and cancer.

Height of the study subjects was measured using stadiometer and the reading was taken to the nearest $0.5 \mathrm{~cm}$. Weight was measured using a weighing machine with the subjects wearing only light clothing. Body mass index (BMI) was calculated as weight in kilogram divided by the square of 
the height in meters $\left(\mathrm{kg} / \mathrm{m}^{2}\right)$. BMI cutoff values for Asians as per the NICE guideline were followed to define obesity as having BMI $\geq 27.5$, overweight with BMI $23-27.5 \mathrm{~kg} / \mathrm{m}^{2}$, normal $18.5-23 \mathrm{~kg} / \mathrm{m}^{2}$, and underweight $<18.5 \mathrm{~kg} / \mathrm{m}^{2}$ [20]. The body surface area (BSA) was determined by Dubois formula (BSA $=0.007184 \times$ Height $^{0.725} \times$ Weight $^{0.425}$ ) [21]. Blood pressure was measured using standardized mercury sphygmomanometer to determine brachial artery systolic (SBP) and diastolic blood pressure (DBP). The blood pressure was measured by a cardiologist after $5 \mathrm{~min}$ rest in erect sitting posture over the left upper arm of the study subjects. The first and fifth Korotkoff sounds were taken as SBP and DBP. The blood pressure $\geq 140 / 90 \mathrm{mmHg}$ was considered to be hypertensive according to JNC7 criteria. The blood pressure was taken as mean of two readings measured under standardized conditions. 2D and M-mode echocardiography was performed in all the study participants using a commercially available GE Vivid E9 with XD clear (echocardiography machine equipped with a broadband transducer) in supine left lateral decubitus position. All echocardiographic measurements were performed by a cardiologist. Readings were taken as per the American Society of Echocardiography (ASE) recommendation. The M-mode derived parasternal view was used to assess the chamber and wall dimensions of the left ventricle and left atrium (LA). The ASE recommended Devereux formula was used for the estimation of the LV mass (LVM) from LV linear dimensions [LVM (g) = 1.04 ((LVIDd + IVSd + LVPWd)3 - LVIDd3) - 13.6, where, LVID = LV internal diameter at end diastole, IVSD = interventricular septal wall thickness at end diastole, LVPWD $=\mathrm{LV}$ posterior wall thickness at end diastole].

LVM index (LVMI) was obtained as a ratio of LVM and BSA (LVM/ BSA). Gender-specific and indexation of LVM was used to diagnose LVH using the defining criteria for men and women, respectively [22]. LVH was defined by LVMI thresholds of $125 \mathrm{~g} / \mathrm{m}^{2}$ for men and $110 \mathrm{~g} /$ $\mathrm{m}^{2}$ for women. The relative wall thickness (RWT) was calculated using the formula $\times 2$ LVPWD/LVID and considered as increased when it is $>0.42$ [23]. RWT and LVMI were used to define LV geometric patterns. LV geometry was divided into four patterns based on LVMI and RWT values; normal geometry: Normal LVMI and RWT $\leq 0.42$, concentric remodeling: Normal LVMI and RWT $>0.42$, eccentric hypertrophy: Increased LVMI and RWT $\leq 0.42$, and concentric hypertrophy: Increased LVMI and RWT $>0.42$. LA size was determined with parasternal long axis view at end systole along its greatest dimension.

\section{Statistical analysis}

All the data were compiled and analyzed using SPSS version 21.0 software and values were expressed as mean, standard deviation, proportion, odds ratio, and $95 \%$ confidence interval. Univariate and multivariate logistic regression analyses were used to explore the associations between LVH as dependent variable and sociodemographic and individual characteristics as independent variables. The variables found to have $\mathrm{p}<0.2$ in univariate analyses were entered into multivariate model. $\mathrm{p}<0.05$ was considered as statistically significant.

\section{RESULTS}

Of 400 study respondents, 247 (61.7\%) were male and rest were female. The mean age of study population was $52.3 \pm 12.8$ years. The mean BMI was $26.7 \pm 4.6$ and the mean BSA was $1.6 \pm 0.2$. The mean SBP and DBP was $149.8 \pm 11.2$ and $94.7 \pm 4.9 \mathrm{mmHg}$, respectively.

The sociodemographic characteristics of study population were shown in Table 1. Majority (50.7\%) of respondents belongs to age range of $41-60$ years and $30.2 \%$ were $>60$ years old. About $331(82.7 \%)$ respondents were overweight or obese. It was observed that almost two-third of hypertensive patients had LVH. Variables such as BMI, SBP, DBP, and left atrial diameter were found significantly associated with LVH in hypertensive patients.

Table 2 summarizes the LV geometric pattern among the hypertensive study population. Abnormal LV geometry was seen in almost all study subjects (98.7\%). Concentric hypertrophy was the predominant (64.3\%) pattern followed by concentric remodeling (32.3\%) among the hypertensives.
Multivariate analysis showing associations of variables with LVH is given in Table 3. Left atrial diameter lost its significance, whereas BMI, SBP, and DBP retained their significance in predicting LVH among the hypertensive patients.

\section{DISCUSSION}

Our study revealed that $66.5 \%$ of hypertensive patients had developed $\mathrm{LVH}$. This figure was comparable to the prevalence of $58.3-75.3 \%$ [24-26] in various studies which used the same LVH criteria as in our study. It was higher compared to many other studies, which reported prevalence of LVH between $26.8 \%$ and $46.0 \%$ [27-30]. As for LV geometric patterns, we observed that the concentric pattern was more prevalent among hypertensive patients. Different studies have shown the association of incremental risk of abnormal geometric patterns, with highest in concentric hypertrophy, followed by eccentric hypertrophy and concentric remodeling [31-34]. The study by Patel et al. and Potu et al. revealed that concentric remodeling (38.5-52.1\% and 30\%) was the most common abnormal geometry in the hypertensive population followed by concentric hypertrophy (15.3-28.9\% and 14\%) and eccentric hypertrophy (3.99-10.3\% and $11 \%$ ) which was the least common type of abnormal geometry $[35,36]$. Studies showed that eccentric hypertrophy was the most common abnormal geometry found in hypertensive population by Adebiyi et al., Cuspidi et al., and Wachtell et al. $[19,37,38]$ whereas Akintunde et al. found that majority of hypertensive subjects had concentric remodeling [39]. There is global and cellular change in the ventricular shape and function in cardiac remodeling. This follows chamber dilation, interstitial and perivascular fibrosis which lead to chronic heart failure [40]. There is an increasing body of evidence and controversies about the role of gender in developing LVH $[12,13,15,19]$. Our study did not show significant difference between gender and LVH.

Previous studies reported that patients with obesity had a higher risk of developing LVH [40-45]. In this study, obesity was found to be one of the predictors for developing LVH among hypertensive patients. The odds of developing $\mathrm{LVH}$ were twice in an obese patient compared to a patient who had normal weight. Further, the odds of developing LVH were 1.4 times higher for an obese patient compared to an overweight patient, but this is statistically insignificant. Kathrotia et al. also showed similar trend in association of obesity with LVH [46]. This might be related to obesity cardiomyopathy which is characterized by the presence of LVH [47]. We also observed that SBP and DBP were two independent determinants for LVH which indicates that reduction of SBP or DBP would significantly regress LVH. This finding is supported by various literature [48-50]. Thus, blood pressure management targeting both SBP and DBP would be useful in preventing the development of LVH. The left atrial enlargement is a predictor for overall cardiovascular risk and frequently found in hypertensive patients as reported by Cuspidi et al. [19]. This abnormality was strongly related to LVH [51-53]. This study showed that LVH was 1.4 times more likely among hypertensives with one unit increase in left atrial diameter $(\mathrm{p}=0.088)$. For this reason, European Society of Cardiology strongly recommends the measurement of left atrial size in echocardiography.

Our study few limitations. First, the result of the study may not be generalized to other settings since it was limited to one tertiary care hospital in Bhubaneswar. Second, causal association of the factors with the development of LVH cannot be established due to cross-sectional nature of the study. However, in spite of these limitations, the findings of our study might be useful in developing strategies to identify LVH among hypertensive patients.

\section{CONCLUSION}

LVH is the alarming and significant rising condition in hypertension. The prevalence of LVH was high in hypertensive patients as found in our study. Efforts should be made for early detection of LVH with liberal use of echocardiography in these patients which will guide appropriate 
Table 1: Sociodemographic characteristics of study population by echocardiographic LVH status ( $n=400)$

\begin{tabular}{|c|c|c|c|}
\hline Variable & No LVH n=134 (\%) & LVH n=266 (\%) & p value \\
\hline \multicolumn{4}{|l|}{ Age in years } \\
\hline $20-40$ & $32(42.1)$ & $44(57.9)$ & \multirow[t]{3}{*}{0.164} \\
\hline $41-60$ & $61(30.0)$ & $142(70.0)$ & \\
\hline$>60$ & $41(33.9)$ & $80(66.1)$ & \\
\hline \multicolumn{4}{|l|}{ Gender } \\
\hline Male & $75(30.4)$ & $172(69.6)$ & \multirow[t]{2}{*}{0.091} \\
\hline Female & 59 (38.6) & $94(61.4)$ & \\
\hline \multicolumn{4}{|l|}{ BMI } \\
\hline Normal & 35 (50.7) & $34(49.3)$ & \multirow[t]{3}{*}{0.000} \\
\hline Overweight & 70 (38.3) & $113(61.7)$ & \\
\hline Obesity & 29 (19.6) & 119 (80.4) & \\
\hline Mean age in years & $50.69 \pm 14.09$ & $53.12 \pm 12.12$ & 0.353 \\
\hline $\mathrm{SBP}(\mathrm{mmHg})$ & $144.01 \pm 6.49$ & $152.77 \pm 11.89$ & 0.000 \\
\hline DBP (mmHg) & $92.10 \pm 3.23$ & $96.01 \pm 5.14$ & 0.000 \\
\hline BMI $\left(\mathrm{Kg} / \mathrm{m}^{2}\right)$ & $25.13 \pm 3.63$ & $27.49 \pm 4.79$ & 0.000 \\
\hline Left atrial & $3.24 \pm 0.63$ & $3.49 \pm 0.64$ & 0.000 \\
\hline diameter $(\mathrm{cm})$ & & & \\
\hline$A V \operatorname{cusp}(\mathrm{cm})$ & $1.57 \pm 0.26$ & $1.57 \pm 0.26$ & 0.939 \\
\hline
\end{tabular}

Table 2: LV geometric patterns among the study population $(n=400)$

\begin{tabular}{ll}
\hline Geometric pattern & $\mathbf{n}(\%)$ \\
\hline Normal & $05(1.3)$ \\
Concentric remodeling & $129(32.3)$ \\
Eccentric hypertrophy & $09(2.3)$ \\
Concentric hypertrophy & $257(64.3)$ \\
\hline
\end{tabular}

Table 3: Multivariate analysis showing determinants of LVH

\begin{tabular}{|c|c|c|c|}
\hline Variable & Odds ratio & $95 \% \mathrm{CI}$ & p value* \\
\hline \multicolumn{4}{|l|}{ Age in years } \\
\hline $20-40$ & 1.02 & $0.51-2.04$ & 0.956 \\
\hline $41-60$ & 1.63 & $0.93-2.87$ & 0.090 \\
\hline$>60$ & 1 & & \\
\hline \multicolumn{4}{|l|}{ Gender } \\
\hline Male & 0.78 & $0.46-1.30$ & 0.340 \\
\hline Female & & 1 & \\
\hline \multicolumn{4}{|l|}{ BMI } \\
\hline Normal & 0.47 & $0.23-0.98$ & 0.043 \\
\hline Overweight & 0.69 & $0.39-1.22$ & 0.199 \\
\hline Obesity & 1 & & \\
\hline SBP & 1.10 & $1.04-1.15$ & 0.000 \\
\hline DBP & 1.11 & $1.01-1.22$ & 0.027 \\
\hline Left atrial diameter & 1.41 & $0.95-2.09$ & 0.088 \\
\hline
\end{tabular}

treatment decision, and thus further cardiovascular complications can be prevented.

\section{ACKNOWLEDGMENT}

The authors are extremely grateful to the staff of the Department of Cardiology, IMS and SUM Hospital of Siksha "O" Anusandhan University, for their constant support in carrying out this study.

\section{CONFLICT OF INTEREST}

All the authors hereby declare that there is no conflict of interest.

\section{AUTHOR CONTRIBUTIONS}

All authors have made substantial contributions to the work reported in the manuscript. Anugya Aparajita Behera: Conception and designing of the study, data collection, data analysis and interpretation, drafting the article, critical revision of the article, final approval of the study to be published. Dr. Priyambada Panda: Drafting the article, critical revision of the article, final approval of the study to be published. Dr. Dipti Mohapatra: Data analysis and interpretation, drafting the article, critical revision of the article, final approval of the study to be published. Dr. Suresh Kumar Behera: Data collection, data analysis and interpretation, drafting the article, critical revision of the article, final approval of the study to be published. Dr. Arati Mohanty: Conception and designing of the study, drafting the article, critical revision of the article, final approval of the study to be published.

\section{AUTHORS CONTRIBUTION}

All authors have made substantial contributions to the work reported in the manuscript. Anugya Aparajita Behera: Conception and designing of the study, data collection, data analysis and interpretation, drafting the article, critical revision of the article, final approval of the study to be published. Dr. Priyambada Panda: Drafting the article, critical revision of the article, final approval of the study to be published. Dr. Dipti Mohapatra: Data analysis and interpretation, drafting the article, critical revision of the article, final approval of the study to be published. Dr. Suresh Kumar Behera: Data collection, data analysis and interpretation, drafting the article, critical revision of the article, final approval of the study to be published. Dr. Arati Mohanty: Conception and designing of the study, drafting the article, critical revision of the article, final approval of the study to be published.

\section{CONFLICTS OF INTERESTS}

All the authors hereby declare that there is no conflict of interest.

\section{REFERENCES}

1. WHO. WHO Cardiovascular Diseases (CVDs). Cardiovascular Diseases (CVDs); 2015. Available from: http://www.who.int/ mediacenter/factsheets/fs $317 \mathrm{en}$.

2. Kearney PM, Whelton M, Reynolds K, Muntner P, Whelton PK, He J, et al. Global burden of hypertension: Analysis of worldwide data. Lancet 2005;365:217-23

3. Soubra L, Nureddin H, Omar AG, Saleh M. Factors associated with hypertension prevalence and control among lebanese Type 2 diabetic patients. Int J Pharm Pharm Sci 2016;8:153-9.

4. Cushman WC, Evans GW, Byington RP, David C, Grimm RH, Cutler JA, et al. Effects of intensive blood-pressure control in Type 2 diabetes mellitus. Engl J Med 2010;362:1575-85. Available from: http://www.nejm.org/doi/abs/10.1056/NEJMoa1001286.

5. WHO. Preventing Chronic Disease: A Vital Investment. Geneva: World Health; 2005. p. 13.

6. Gupta R. Trends in hypertension epidemiology in India. Hum 
Hypertens 2004;18:73-8. Available from: http://www.nature.com/ doifinder/10.1038/sj.jhh.1001633.

7. Jose A, Wilson D, George M, Thomas RK, Justin A. Comparative study on the beneficial effects of telmisartan and other antihypertensive agents in stroke patients. Int J Pharm Pharm Sci 2017;9:99. Available from: http://www.innovareacademics.in/journals/index.php/ijpps/ article/view/15755.

8. Dahlof B, Devereux BR, Kjeldsen SE. Cardiovascular morbidity and mortality in the losartan intervention for end point reduction in hypertension study (LIFE): A randomised trial against atenolol. ACC Curr J Rev 2002;11:26. Available from: http://www.linkinghub.elsevier. com/retrieve/pii/S1062145802007778.

9. Sforza VF. European society of hypertension - European society of cardiology guidelines for the management of arterial hypertension. A J Hypertens 2003;21:1011-54.

10. Sundström J, Lind L, Arnlöv J, Zethelius B, Andrén B, Lithell HO. Echocardiographic and electrocardiographic diagnoses of left ventricular hypertrophy predict mortality independently of each other in a population of elderly men. Circulation 2001;103:2346-51. Available from: http://www.ncbi.nlm.nih.gov/pubmed/11352882.

11. Ruilope LM, Schmieder RE. Left ventricular hypertrophy and clinical outcomes in hypertensive patients. Am J Hypertens 2008;21:500-8. Available from: https://www.academic.oup.com/ajh/article-lookup/ doi/10.1038/ajh.2008.16.

12. Barrios V, Escobar C, Calderon A, Ribas L, Marti D, Asin E, et al. Prevalence of left ventricular hypertrophy detected by cornell voltage-duration product in a hypertensive population. Blood Press 2008; $17: 110-5$.

13. Lozano JV, Redon J, Cea-Calvo L, Fernandez-Perez C, Navarro J, Bonet A, et al. Left ventricular hypertrophy in the Spanish hypertensive population. The ERIC-HTA study. Rev Esp Cardiol 2006;59:136-42.

14. Mancia G, Carugo S, Grassi G, Lanzarotti A, Schiavina R, Cesana G, et al. Prevalence of left ventricular hypertrophy in hypertensive patients without and with blood pressure control: Data from the PAMELA population. Pressioni arteriose monitorate E loro associazioni. Hypertension 2002;39:744-9.

15. de Simone G, Devereux RB, Roman MJ, Alderman MH, Laragh JH. Relation of obesity and gender to left ventricular hypertrophy in normotensive and hypertensive adults. Hypertension 1994;23:600-6.

16. Hammond IW, Devereux RB, Alderman MH, Laragh JH. Relation of blood pressure and body build to left ventricular mass in normotensive and hypertensive employed adults. Am Coll Cardiol 1988;12:996-1004.

17. Ching SM, Chia YC, Wan Azman WA. Prevalence and determinants of left ventricular hypertrophy in hypertensive patients at a primary. Care Clin 2012;7:2-9.

18. Institute for Health Management, Ministry of Health Malaysia. A study on the adequacy. Outpatient Management of Essential Hypertension in $\mathrm{MOH}$ Hospitals and Health Centres. Sydney: Institute for Health Management; 2006.

19. Cuspidi C, Sala C, Negri F, Mancia G, Morganti A. Prevalence of left-ventricular hypertrophy in hypertension: An updated review of echocardiographic studies. Hum Hypertens 2012;26:343-49. Available from: http://www.nature.com/doifinder/10.1038/jhh.2011.104

20. NICE Guidance. BMI: Preventing Ill Health and Premature Death in Black, Asian and Other Minority Ethnic Groups; 2013. Available from: https://www.nice.org.uk/guidance/ph46/chapter/1-recommendations. [Last cited on 2017 Sep 30].

21. Du Bois D, Du Bois EF. A formula to estimate the approximate surface area if height and weight be known 1916. Nutrition 1989;5:303-11.

22. Levy D, Savage DD, Garrison RJ, Anderson KM, Kannel WB, Castelli WP, et al. Echocardiographic criteria for left ventricular hypertrophy: The framingham heart study. Am J Cardiol 1987;59:95660.

23. Devereux RB, Alonso DR, Lutas EM, Gottlieb GJ, Campo E, Sachs I, et al. Echocardiographic assessment of left ventricular hypertrophy: Comparison to necropsy findings. Am J Cardiol 1986;57:450-8. Available from: http://www.sci-hub.bz/10.1016/0002-9149(86)90771$\mathrm{x} \% 5 \mathrm{Cnhttp}: / / \mathrm{www}$. sciencedirect.com/science/article/B6T104C7097R-WB/2/4199faad332cc441e1dd612c3ad637b9.

24. Iwashima Y, Horio T, Kamide K, Tokudome T, Yoshihara F, Nakamura S, et al. Additive interaction of metabolic syndrome and chronic kidney disease on cardiac hypertrophy, and risk of cardiovascular disease in hypertension. Am J Hypertens 2010;23:290-8.

25. Yasuno S, Ueshima K, Oba K, Fujimoto A, Ogihara T, Saruta T, et al. Clinical significance of left ventricular hypertrophy and changes in left ventricular mass in high-risk hypertensive patients: A subanalysis of the candesartan antihypertensive survival evaluation in Japan trial.
J Hypertens 2009;27:1705-12

26. Castelpoggi CH, Pereira VS, Fiszman R, Cardoso CR, Muxfeldt ES, Salles GF, et al. A blunted decrease in nocturnal blood pressure is independently associated with increased aortic stiffness in patients with resistant hypertension. Hypertens Res 2009;32:591-6.

27. Cuspidi C, Giudici V, Lonati L, Sala C, Valerio C, Mancia G, et al. Left ventricular hypertrophy detection and body mass index in essential hypertension. Blood Press 2010;19:337-43.

28. Cuspidi C, Ambrosioni E, Mancia G, Pessina AC, Trimarco B, Zanchetti A, et al. Role of echocardiography and carotid ultrasonography in stratifying risk in patients with essential hypertension: The assessment of prognostic risk observational survey. J Hypertens 2002;20:1307-14.

29. Viazzi F, Parodi D, Leoncini G, Parodi A, Falqui V, Ratto E, et al. Serum uric acid and target organ damage in primary hypertension. Hypertension 2005;45:991-6.

30. Tsioufis CP, Tsiachris DL, Selima MN, Dimitriadis KS, Thomopoulos CG, Tsiliggiris DC, et al. Impact of waist circumference on cardiac penotype in hypertensives according to gender. Obesity 2009; 17:177-82.

31. Ganau A, Devereux RB, Roman MJ, de Simone G, Pickering TG, Saba PS, et al. Patterns of left ventricular hypertrophy and geometric remodeling in essential hypertension. J Am Coll Cardiol 1992;19:1550-8.

32. Schillaci G, Verdecchia P, Porcellati C, Cuccurullo O, Cosco C, Perticone $\mathrm{F}$, et al. Continuous relation between left ventricular mass and cardiovascular risk in essential hypertension. Hypertension 2000;35:580-6.

33. Haider AW, Larson MG, Benjamin EJ, Levy D. Increased left ventricular mass and hypertrophy are associated with increased risk for sudden death. Am Coll Cardiol 1998;32:1454-59.

34. Shipilova T, Pshenichnikov I, Kaik J, Volozh O, Abina J, Kalev M, et al. Echocardiographic assessment of the different left ventricular geometric patterns in middle-aged men and women in tallinn. Blood Press 2003;12:284-90.

35. Potu C, Tulloch-Reid E, Baugh D, Ismail OA, Madu EC. Echocardiographic partition values and prevalence of left ventricular hypertrophy in hypertensive jamaicans. Eur J Cardiovasc Med 2012;2:70-7. Available from: http://www.healthcare-bulletin. com/journals/cardiovascular-medicine/the-european-journalof-cardiovascular-medicine/details/article/echocardiographicpartition-values-and-prevalence-of-left-ventricular-hypertrophy-inhypertensive-ja/.

36. Patel DA, Lavie CJ, Artham SM, Milani RV. Cardenas GA, Ventura HO. Effects of left ventricular geometry and obesity on mortality in women with normal ejection fraction. Am J Cardiol 2014;113:877-80. Available from: http://www.linkinghub.elsevier.com/retrieve/pii/ S0002914913023862.

37. Adebiyi AA, Ogah OS, Aje A, Ojji DB, Adebayo AK, Oladapo OO, et al. Echocardiographic partition values and prevalence of left ventricular hypertrophy in hypertensive Nigerians. BMC Med Imaging 2006;6:10. Available from: http://www.bmcmedimaging.biomedcentral.com/ articles/10.1186/1471-2342-6-10

38. Wachtell K, Bella JN, Liebson PR, Gerdts E, Dahlöf B, Aalto T, et al. Impact of different partition values on prevalences of left ventricular hypertrophy and concentric geometry in a large hypertensive population : The LIFE study. Hypertension 2000;35:6-12.

39. Akintunde A, Akinwusi O, Opadijo G. Left ventricular hypertrophy, geometric patterns and clinical correlates among treated hypertensive nigerians. Pan Afr Med J 2010;4:8.

40. Choi D, Hwang KC, Lee KY, Kim YH. Ischemic heart diseases: Current treatments and future. J Control Release 2009;140:194-202.

41. Schirmer H, Lunde P, Rasmussen K. Prevalence of left ventricular hypertrophy in a general population; The tromsø study. Eur Heart J 1999;20:429-38

42. Salvetti G, Pucci A, Fierabracci P, Ceccarini G, Palagi C, Donne MGD, et al. Prevalence of left ventricular hypertrophy and determinants of left ventricular mass in obese women. High Blood Press Cardiovasc Prev 2012;19:33-9. Available from: http://www.scopus.com/inward/record. url?eid=2-s2.0-84861950539\&partnerID $=40 \& \mathrm{md} 5=\mathrm{a} 2 \mathrm{~d} 401 \mathrm{c} 7 \mathrm{cc} 80138$ 805c9337b9607f147

43. Lauer MS, Anderson KM, Kannel WB, Levy D. The impact of obesity on left ventricular mass and geometry. The framingham heart study. JAMA 1991;266:231-6.

44. Chadha DS, Gupta N, Goel K, Pandey RM, Kondal D, Ganjoo RK, et $a l$. Impact of obesity on the left ventricular functions and morphology of healthy asian indians. Metab Syndr Relat Disord 2009;7:151-8.

45. Wong CY, O’Moore-Sullivan T, Leano R, Byrne N, Beller E, 
Marwick TH, et al. Alterations of left ventricular myocardial characteristics associated with obesity. Circulation 2004;110:3081-7.

46. Kathrotia RG, Paralikar SJ, Rao PV, Oommen ER. Impact of different grades of body mass index on left ventricular structure and function. Indian J Physiol Pharmacol 2010;54:149-56.

47. Alpert MA. Obesity cardiomyopathy: Pathophysiology and evolution of the clinical syndrome. Am J Med Sci 2001;321:225-36.

48. Zhang K, Chen J, Liu Y, Wang T, Wang L, Wang J, et al. Diastolic blood pressure reduction contributes more to the regression of left ventricular hypertrophy: A meta-analysis of randomized controlled trials. Hum Hypertens 2013;27:698-706. Available from: http://www.nature.com/ doifinder/10.1038/jhh.2013.20.

49. de Lima JJ, Abensur H, Edurado MK, Fulvio P. Arterial blood pressure and left ventricular hypertrophy in haemodialysis patients. J Hypertens 1996; $14: 1019-24$

50. Li H, Pei F, Shao L, Chen J, Sun K, Zhang X, et al. Prevalence and risk factors of abnormal left ventricular geometrical patterns in untreated hypertensive patients. BMC Cardiovasc Disord 2014;14:136. Available from: http://www.pubmedcentral.nih.gov/articlerender. fcgi? artid $=4192326 \&$ tool $=$ pmcentrez\&rendertype $=$ abstract.

51. Gerdts E, Oikarinen L, Palmieri V, Otterstad JE, Wachtell K, Boman K, et al. Correlates of left atrial size in hypertensive patients with left ventricular hypertrophy: The losartan intervention for endpoint reduction in hypertension (LIFE) study. Hypertension 2002;39:739-43.

52. Okin PM, Gerdts E, Wachtell K, Oikarinen L, Nieminen MS, Dahlöf B, et al. Relationship of left atrial enlargement to persistence or development of ECG left ventricular hypertrophy in hypertensive patients: Implications for the development of new atrial fibrillation. Hypertens 2010;28:1534-40. Available from: http://www.content. wkhealth.com/linkback/

53. Tedesco MA, Di Salvo G, Ratti G, Natale F, Iarussi D, Iacono A. Left atrial size in 164 hypertensive patients: An echocardiographic and ambulatory blood pressure study. Clin Cardiol 2001;24:603-7. 